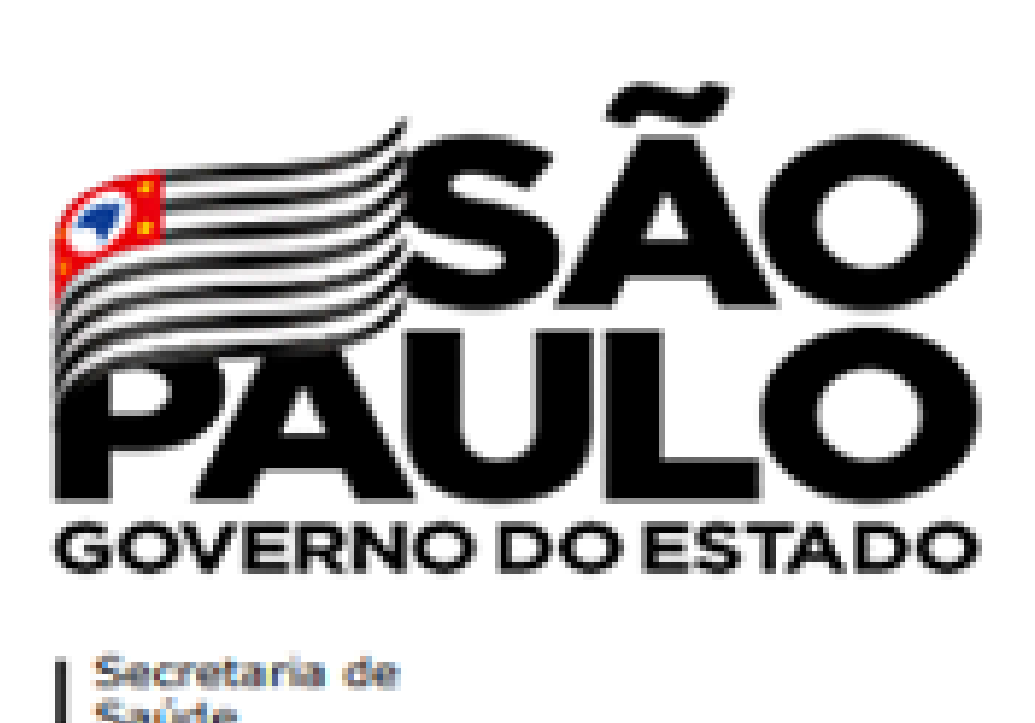

Congresso Internacional

Ana Carolina Siqueira, Hannelore Speierl, Elizabeth Akemi Nishio, Marcelo Ribeiro de Araújo e Lucas Cese Marcheti

\title{
CLASSIFICAÇÃO DE RISCO NA TRIAGEM DE UM SERVIÇO DE DEPENDÊNCIA QUÍMICA
}

\author{
Avaliação e Qualidade do Cuidado
}

\section{INTRODUÇÃO}

A assistência prestada ao paciente com dependência química em crise necessita de padronização, uma vez que há uma variedade de apresentações clínicas e psiquiátricas relacionadas ao uso de drogas. Em 2013 os gestores de um serviço de atendimento de portas abertas para usuários de substancias desenvolveram um protocolo de classificação de risco. O protocolo auxilia os profissionais na avaliação de pacientes e tomada de decisão, levando em consideração a gravidade de cada caso. Esse protocolo tem como base o Protocolo de Manchester, instrumento utilizado mundialmente em serviços de urgências e emergências e foi adaptado para realizar a classificação dos pacientes baseando-se nos sinais e sintomas clínicos e psiquiátricos, proporcionando assim uma assistência mais humanizada, segura e de qualidade.

Com a aplicação do protocolo no primeiro momento de atendimento, Emergências Psiquiátricas e Clínicas recebem uma etiqueta vermelha, urgências Psiquiátricas e Clínicas recebem uma etiqueta amarela e as não urgências são identificadas com a etiqueta verde, e essa classificação é utilizada como critério de priorização de atendimento de acordo com o risco de cada paciente.

Para a implantação segura e sucesso na adesão ao novo protocolo, foi realizada uma capacitação em emergências clínicas e psiquiátricas de toda equipe do serviço, com foco principal em capacitar o enfermeiro que é o responsável pelo primeiro atendimento do usuário e aplicação do protocolo de classificação.

\section{OBJETIVO}

Sistematizar o serviço de triagem de um serviço de emergência para dependência química com a classificação de riscos psiquiátricos e clínicos.

\section{MÉTODO}

Trata-se de um relato experiência, no qual o protocolo de classificação de risco e os treinamentos introduzidos foram os principais instrumentos para monitorar e melhorar a qualidade do serviço.

\section{RESULTADO}

A partir da introdução do protocolo de classificação de risco, podemos monitorar a triagem de forma mais eficiente, garantindo uma assistência de forma padronizada e focada na segurança, que prioriza os casos de emergenciais e reduz os atos violentos durante a espera do atendimento. No fluxo de atendimento do Serviço em referência, os pacientes passam por uma triagem inicial realizada pelo enfermeiro e são avaliados de acordo com os sinais e sintomas que apresentam, após essa avaliação, esse são classificados em grau de gravidade. Os pacientes identificados com etiqueta s que referenciam seu grau de gravidade e seguem o fluxo de atendimento conforme figura 1.
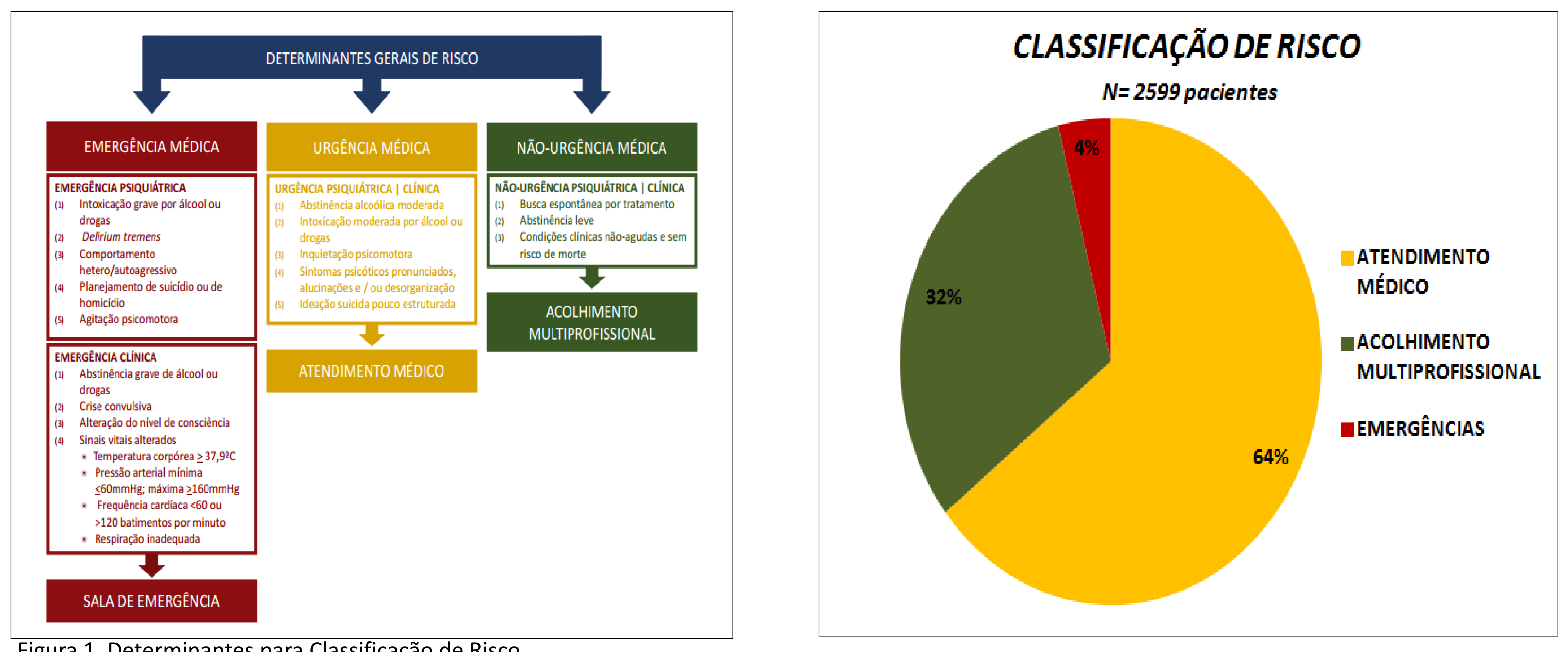

\section{CONCLUSÃO}

A Classificação de Risco proporciona um cuidado pautado na qualidade da assistência prestada ao paciente que busca o serviço de pronto atendimento em dependência química, possibilitando um cuidado seguro e humanizado.

\section{REFERÊNCIAS BIBLIOGRÁFICAS}

Mendes MF, Bastos FMN, Tavares AJP. Eficácia do Acolhimento com Avaliação e Classificação de Risco em Emergência Psiquiátrica. Hospital de Saúde Mental de Messejana (HSMM). Paschel DF, Passos E, Hennington EA. Cinco anos da política nacional de humanização: trajetória de uma política pública. Ciênc. saúde coletiva 2011. 